\title{
Precision prevention of Alzheimer's and other dementias: Anticipating future needs in the control of risk factors and implementation of disease-modifying therapies
}

\author{
Giovanni B. Frisoni ${ }^{1,2}$ | José Luis Molinuevo ${ }^{3}$ | Daniele Altomare ${ }^{1,2}$ | \\ Emmanuel Carrera $^{4}$ | Frederik Barkhof ${ }^{5,6}$ | Johannes Berkhof ${ }^{7}$ | Julien Delrieu ${ }^{8,9}$ | \\ Bruno Dubois $^{10}$ | Miia Kivipelto ${ }^{11,12,13,14}$ | Agneta Nordberg ${ }^{11,12}$ | \\ Jonathan M. Schott ${ }^{15}$ | Wiesje M. van der Flier ${ }^{7,16}$ | Bruno Vellas ${ }^{8,9}$ | \\ Frank Jessen ${ }^{17,18,19}$ | Philip Scheltens ${ }^{16}$ | Craig Ritchie ${ }^{20}$ \\ ${ }^{1}$ Laboratory of Neuroimaging of Aging (LANVIE), University HospitalsUniversity of Geneva, Geneva, Switzerland \\ ${ }^{2}$ Memory Clinic, University Hospitals of Geneva, Geneva, Switzerland \\ ${ }^{3}$ Barcelonaßeta Brain Research Center, Pasqual Maragall Foundation, Barcelona, Spain \\ ${ }^{4}$ Stroke Center, Department of Neurology, University Hospitals and University of Geneva, Geneva, Switzerland \\ ${ }^{5}$ Department of Radiology and Nuclear Medicine, Amsterdam Neuroscience, Vrije Universiteit Amsterdam, Amsterdam UMC, Amsterdam, the Netherlands \\ ${ }^{6}$ Institutes of Neurology and Healthcare Engineering, UCL, London, UK \\ 7 Department of Epidemiology and Biostatistics, Vrije Universiteit Amsterdam, Amsterdam UMC, Amsterdam, the Netherlands \\ ${ }^{8}$ Gérontopole of Toulouse, University Hospital of Toulouse (CHU-Toulouse), Toulouse, France \\ 9 UMR INSERM 1027, University of Toulouse III, Toulouse, France \\ ${ }^{10}$ Institut de la Mémoire et de la Maladie d'Alzheimer, IM2A, INSERM, Institut du Cerveau et de la Moelle Épinière, UMR-S975, Groupe Hospitalier Pitié-Salpêtrière, \\ Sorbonne Université, Paris, France \\ ${ }^{11}$ Department of Neurobiology, Care Sciences and Society, Center for Alzheimer Research, Division of Clinical Geriatrics, Karolinska Institutet, Stockholm, Sweden \\ ${ }^{12}$ Aging Theme, Karolinska University Hospital, Stockholm, Sweden \\ ${ }^{13}$ Institute of Public Health and Clinical Nutrition, School of Medicine, University of Eastern Finland, Kuopio, Finland \\ ${ }^{14}$ School of Public Health, Imperial College, London, UK \\ ${ }^{15}$ Queen Square Institute of Neurology at University College London, London, UK \\ ${ }^{16}$ Alzheimer Center Amsterdam, Department of Neurology, Amsterdam Neuroscience, Vrije Universiteit Amsterdam, Amsterdam UMC, Amsterdam, the Netherlands \\ ${ }^{17}$ Department of Psychiatry and Psychotherapy, Medical Faculty, University of Cologne, Cologne, Germany \\ ${ }^{18}$ Excellence Cluster on Cellular Stress Responses in Aging-Associated Diseases (CECAD), University of Cologne, Cologne, Germany \\ ${ }^{19}$ German Center for Neurodegenerative Diseases (DZNE), Bonn, Germany \\ ${ }^{20}$ Centre for Clinical Brain Sciences, University of Edinburgh, Edinburgh, UK
}

\section{Correspondence}

Giovanni B. Frisoni, Centre de la memoire, Batiment Louise Morier, Rue Gabrielle-PerretGentil 4, 1205 Geneva, Switzerland.

Email:giovanni.frisoni@unige.ch

Funding information

European Prevention of Alzheimer's Dementia consortium, Grant/Award Number: 115736;

Amyloid imaging to prevent Alzheimer's dis-

\section{Abstract}

Empirical evidence suggests that a fair proportion of dementia cases are preventable, that some preventive actions can be taken immediately, and others may soon be implemented. Primary prevention may target cognitively normal persons with modifiable risk factors through lifestyle and multiple domain interventions (including general cardiovascular health). While the effect on individuals may be modest, it might have a large societal impact by decreasing overall dementia incidence by up to $35 \%$. 
ease, Grant/Award Number: 115952; Joint Programming for Neurodegenerative Diseases, Grant/Award Number: 733051102; healthHolland, Top Sector Life Sciences \& Health, Grant/Award Number: LSHM19051-H036
Secondary prevention will target cognitively normal persons at high risk of dementia due to Alzheimer's disease pathology with future anti-amyloid, anti-tau, or other drugs. This approach is likely to have major benefits to both individuals and society. Memory clinics will need structural and functional changes to adapt to novel technologies and increased patients' demands, and brand-new services may need to be developed with specific skills on risk profiling, risk communication, and personalized risk reduction plans.

\section{1 | INTRODUCTION}

Few medical conditions raise as much controversy and as many contradictions among physicians, scientists, and the society at large as dementia. Dementia is a syndrome encompassing, among others, a number of neurodegenerative and cerebrovascular diseases, often presenting in combination, the most frequent of which is Alzheimer's disease (AD). The general mechanism of neurodegeneration has been identified as protein misfolding and aggregation followed by neurotoxicity; some of the molecular culprits have been identified (beta amyloid, hyper-phosphorylated tau, and other neurotoxic proteins) as well as their mode of diffusion to and into the brain. ${ }^{1}$

Symptomatic drugs are available for dementia, and proved to be effective at the group level in a number of clinical trials. ${ }^{2}$ Disease modifying therapies (DMTs) aimed to prevent or delay the onset or progression of cognitive impairment are still under development. Seventeen DMTs specific to AD (10 targeting amyloid, while the other mechanisms include anti-tau, neuroprotection, antiinflammatory approaches, and metabolic interventions) were in phase III (ie, the phase assessing the clinical efficacy of a drug before regulatory registration) in 2019. ${ }^{3}$ Despite different mechanisms of actions, all the AD DMTs tested so far have invariably failed to achieve primary clinical endpoints in phase III trials. The repeated failures of putative DMTs in the last stage of clinical development challenge the scientific community and the amyloid cascade hypothesis, the dominant model of $A D$ pathogenesis.

Despite frustrations over drug development, we believe that a number of studies point to the possibility of implementing evidence-based and scalable prevention programs targeting lifestyle risk factors and medical comorbidities with a precision dementia prevention approach. This entails tailoring risk reduction to the clinical, genetic, and biological characteristics of each patient. Primary prevention aims to reduce disease incidence, either through addressing disease mechanisms or increasing resistance to disease, by targeting persons in the population at a time when they do not yet bear either disease markers or clinical impairment. Secondary prevention aims to detect and target clinically normal individuals with biomarker evidence of disease to delay or prevent symptom onset. Tertiary prevention aims to target patients with clinical impairment to reduce the impact of progressive symptomatic decline. In the following sections, we will address the rationale for primary and secondary dementia prevention with a precision medicine approach; the role of risk factors and their contribution to dementia; future scenarios of primary and secondary prevention of dementia; and foreseeable clinical, scientific, and organizational needs. Tertiary prevention included pharmacological and non-pharmacological interventions routinely carried out in memory clinics and will not be addressed in this article.

\section{I DEMENTIA PREVENTION IS ALREADY IN ACTION: THE SECULAR TREND TO AGE-SPECIFIC INCIDENCE REDUCTION}

According to the findings of the world's largest survey on people's attitudes to dementia (almost 70,000 people across 155 countries and territories), summarized by the recently published "World Alzheimer Report 2019: Attitudes to dementia," even though 54\% of people think that lifestyle plays a role in developing dementia, $25 \%$ of them think, paradoxically, that there is nothing we can do to prevent it. ${ }^{4}$ Despite skepticism in the general public about the possibility of preventing and/or curing AD and other dementing disorders, ${ }^{5}$ epidemiological observations suggest that dementia prevention has been taking place, albeit unintended, for the past 20 years. While the worldwide prevalence of dementia is expected to grow in the next 30 years by $92 \%$ in highand $176 \%$ in low-to-middle-income countries, epidemiological studies have shown decreasing incidence or age-specific prevalence rate of dementia in recent decades in Western countries. ${ }^{6-12}$ In Bronx County, New York, 75- to 79-year-old persons born in 1915 had an incidence rate of dementia approximately 2.5 cases per 100 person/year, while persons of the same age born in 1935 had an incidence rate approximately 0.3 cases per 100 person/year ${ }^{7}$ (Figure 1). Consistently, the Cognitive Function and Ageing Study I and II reported a 20\% drop in dementia incidence in the same geographical areas in the UK over two decades, from 1991 to $2011 .^{12}$ Moreover, a decreased prevalence of brain amyloid pathology, a key AD marker, has been found in 1599 brain autopsies from 1972 to $2006 .{ }^{13}$ This phenomenon has not yet been observed in low-to-middle-income countries.

The determinants of the age-specific incidence reduction cannot be ascertained definitely in a post-hoc manner. However, it is likely that improvements in lifestyles (eg, more physical activity, longer formal education, healthier nutrition, and reduced smoking) and medical advances (eg, better control of vascular risk factors) in the general population may have played, and are still playing, a major role $\mathrm{e}^{6,11}$ perhaps via a strengthened neural reserve. Indeed, cerebrovascular 


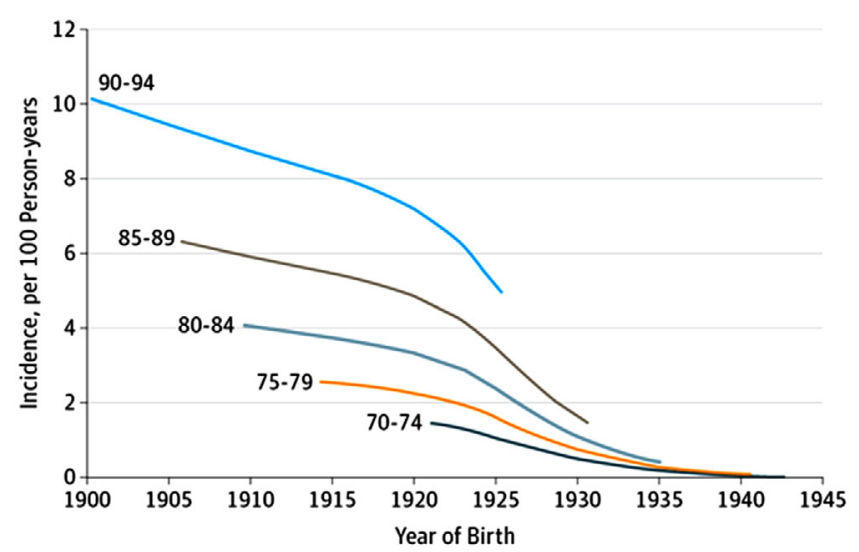

FIGURE 1 Dementia prevention in action: secular trend of decreased incidence of dementia as a function of date of birth and age in the Einstein Aging Study. Figure taken from: Derby et al. ${ }^{7}$

disease, usually in the form of microangiopathy, often accompanies neurodegeneration and $\mathrm{AD}$ pathology, ${ }^{14}$ and cerebrovascular health has recently been improved in the general population through a better control of cardiovascular risk factors.

These observations suggest that dementia prevention is not only possible but is already in action. While this beneficial effect is likely to have come as an unintended byproduct of the secular trend to greater wealth and healthier lifestyles in higher-income societies, the future incremental improvements required to counteract the demographic pressure of an aging world will need to be deliberated, planned, and equitable. Moreover, the rise in rates of obesity and diabetes in recent years may offset the gains made in existing cohorts entering the peak incidence period for dementia in the future. For such programs to be effective and efficient, sound knowledge is paramount about which risk factors are at work, at which stage of the life course, and their strength at both the individual and population levels.

\section{3 | RISK FACTORS AND THEIR CONTRIBUTION TO DEMENTIA}

What constitutes a risk factor for a given disease depends on the definition of the disease itself. The definition and the very concept of $A D$ as a disease are rapidly evolving. Consequently, what should be regarded as a risk factor for the disease is also changing. ${ }^{5}$ For example, the most recent diagnostic criteria and research framework for $A D$ stipulate that combined amyloidosis and tauopathy define the disease irrespective of cognitive symptoms and impairment, ${ }^{15,16}$ while isolated amyloidosis is considered either a risk factor for AD (Preclinical Expert Consensus, $2016^{15}$ ) or "Alzheimer's pathologic change" along the "Alzheimer's continuum" (National Institute on Aging-Alzheimer's Association, NIA-AA, Research Framework, 2018 ${ }^{16}$ ). While not challenging the NIA-AA's current conceptualization of AD as the association of brain amyloidosis and tauopathy, we believe that these conditions can also be regarded as strong risk factors for $A D .^{5}$
In 2018, the Lancet Commission on Dementia Prevention, Intervention, and Care estimated that approximately $35 \%$ of dementia is attributable to nine modifiable risk factors (Figure 2). ${ }^{17}$ Of these, five are general vascular disease risk factors (hypertension, obesity, smoking, physical inactivity, and diabetes), while four are more specific to dementia (low education, hearing loss, depression, and social isolation). While their prevalence varies from $3 \%$ to $40 \%$, what is common to all is the relatively low relative risk for dementia, ranging between 1.4 and 1.9 (Figure 2). Specifically, vascular risk factors have been vigorously tacked over the years because of their association with severe events other than dementia with significant impact on health (eg, stroke and myocardial infarction). On the contrary, psychosocial (or dementia-specific) risk factors are usually not associated with other severe events by themselves (except for depression, which may lead to suicide) and, thus, are considered less dangerous and have received less attention from a public health perspective. Nevertheless, we strongly recommend the study of psychosocial risk factors. This is further supported by the notion that dementia is the major adverse health outcome associated with these risk factors. Future personalized risk reduction protocols need to adopt a multidomain approach by targeting subject-specific risk factors, whether vascular or psychosocial.

Current evidence indicates that brain amyloidosis and tauopathy account for a large part of the remaining dementia risk (although the interplay among risk factors is still not clear and should be further elucidated). Indeed, brain amyloidosis with or without tauopathy and brain amyloidosis plus tauopathy are associated with a much greater risk for dementia (hazard ratio of 13.0 and 23.6, respectively; Figure 2) than modifiable risk factors (relative risk between 1.4 and 1.9). This greater risk, combined with the prevalence of amyloidosis and tauopathy in a population of cognitively normal (CN) persons over 65 years of age ( $31 \%$ and $16 \%$ respectively), indicates that treatment of amyloidosis and tauopathy might result in a drastic reduction of dementia incidence (Figure 2).

Unfortunately, current risk estimates address one or few risk factors, preventing an appropriate adjustment for communality (the variance in observed variables accounted for by common factors). Future large population-based studies collecting information on traditional risk factors as well as genetic risk factors and molecular pathology will allow more accurate estimates of the individual risk and population attributable fraction.

\section{I PRIMARY PREVENTION ON MODIFIABLE VASCULAR AND NON-VASCULAR RISK FACTORS}

While effective DMTs are yet to be developed, prevention programs in persons with no clinical cognitive and behavioral impairment and high risk due to modifiable risk factors are the only means of tackling dementia incidence. The World Health Organization assessed and summarized the evidence currently available and published guidelines entitled Risk Reduction of Cognitive Decline and Dementia, focusing on different interventions (including physical activity, nutrition, and management of cardiovascular risk factors), ${ }^{18}$ that might be the basis for 


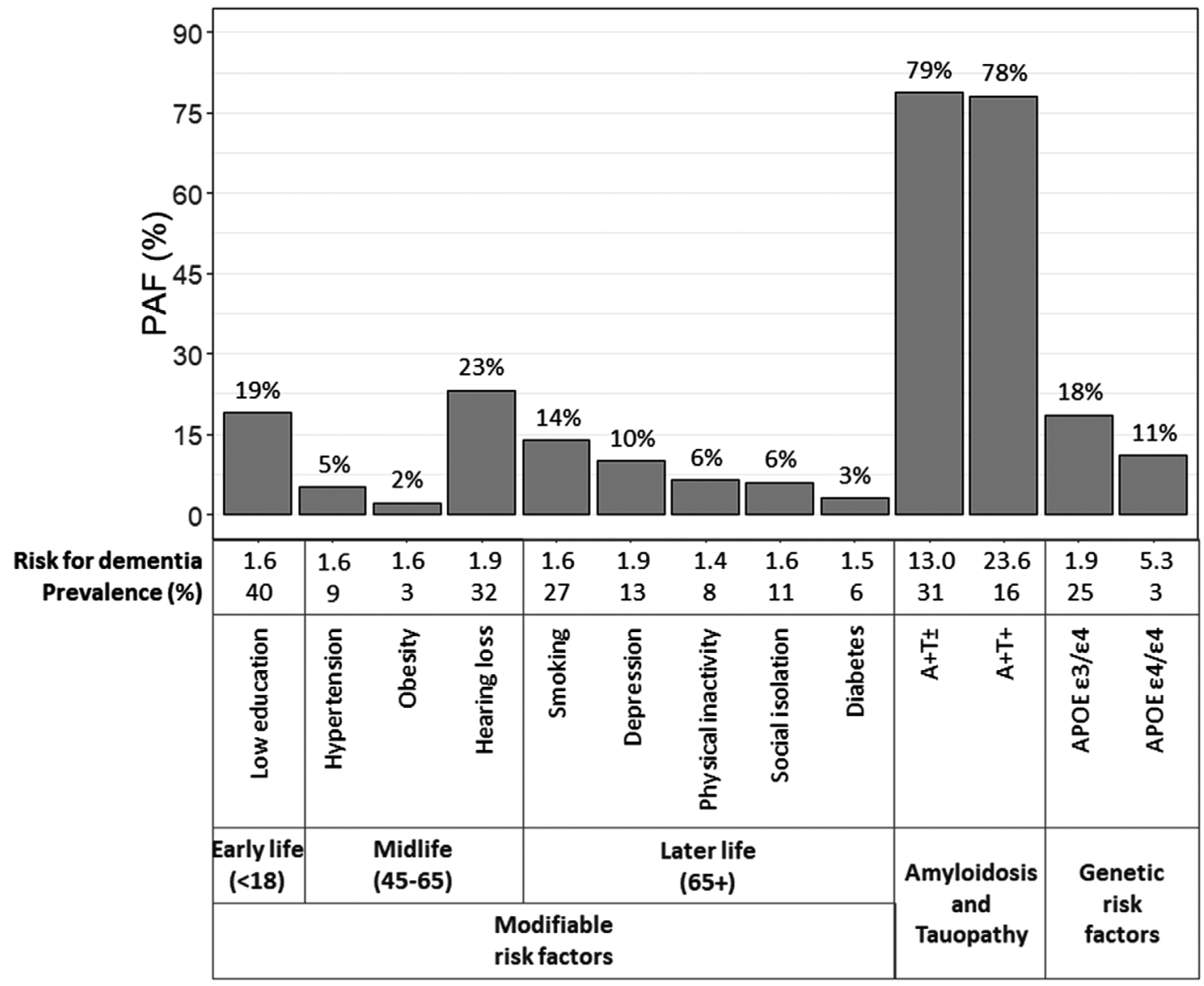

FIG URE 2 Risk factors for dementia and Alzheimer's disease and their corresponding population attributable fraction (PAF, the proportion of cases that might be spared by full control of the risk factor). PAF figures are unadjusted for communality (the variance in observed variables accounted for by common factors) for a fair comparison among risk factors based on available literature data. Risk for incident dementia: relative risk for lifestyle risk factors, subdistribution hazard ratios for biological, and hazard ratio for genetic risk factors. $P A F=P(R R-1) /(1+P(R R-1)$ ) where $\mathrm{P}$ is the prevalence of the risk factor in the population, and RR is the unadjusted relative risk for dementia associated with the risk factor. ${ }^{17}$ See "Commentary", in the Supplementary material, for further information about PAF computation

the development and implementation of evidence-based interventions. To date, encouraging evidence suggests that a precision prevention approach (personalized prevention plans) can maximize the benefit of risk reduction programs based on lifestyle and pharmacologic interventions. When implemented, the impact at the societal level could be significant.

\subsection{Lifestyle risk factors and multidomain interventions}

Dementia is a syndrome often resulting from a combination of several factors, and recent evidence suggests that multidomain interventions should yield greater impact than interventions on individual factors. To date, only four large multidomain trials for all-cause dementia prevention and three on general cardiovascular risk reductionhave been completed (Table 1; for an exhaustive review on lifestyle interventions, see Kivipelto et al. ${ }^{19}$ ). Among the multidomain trials, FINGER (Finnish Geriatric Intervention Study to Prevent Cognitive Impairment and Disability $)^{20}$ was the only one to find a significant difference in the primary outcome (change in cognitive performance on the neuropsychological test battery [NTB]), whose clinical significance remains to be demonstrated, between the intervention and control groups. LIFE (Lifestyle Interventions and Independence for Elders) is a trial with a physical activity program focusing on mild aerobic exercise, strength, muscle flexibility, and balance in the old and very old that showed efficacy of the intervention on cognitive frailty ${ }^{21}$. A recent study on hypertensive patients showed that treatment with low-dose rosuvastatin can reduce cognitive decline and incidence of cognitive impairment. $^{22}$ On the other hand, the MAPT (Multidomain Alzheimer Preventive Trial), ${ }^{23}$ PreDIVA (Prevention of Dementia by Intensive Vascular Care), ${ }^{24}$ Look AHEAD (Action for Health in Diabetes), ${ }^{25}$ and SPRINT MIND (Systolic Blood Pressure Intervention Trial-Memory and Cognition in Decreased Hypertention) trials failed to show positive effects of the interventions on their predefined primary outcomes.

Interestingly, FINGER, MAPT, and SPRINT MIND showed concordant effects in subgroups of participants at higher risk for dementia. In FINGER, the beneficial effect of the intervention on some 
TAB LE 1 Overview of randomized trials on multidomain interventions and general cardiovascular risk reduction for the prevention of dementia and cognitive impairment

\begin{tabular}{|c|c|c|c|c|c|}
\hline Trial & Population & Study design & Primary outcome & Results & Exploratory analyses \\
\hline \multicolumn{6}{|l|}{$\begin{array}{l}\text { Multidomain } \\
\text { interventions }\end{array}$} \\
\hline FINGER $^{20}$ & $\begin{array}{l}N=1,260, \text { age } 60-77 \\
\text { CAIDE risk score } \geq 6\end{array}$ & $\begin{array}{l}\text { Randomized, } \\
\text { double-blind. } \\
\text { Intervention: diet, } \\
\text { physical exercise, } \\
\text { cognitive training, and } \\
\text { vascular risk } \\
\text { monitoring. } \\
\text { Control: traditional } \\
\text { health advice. } \\
\text { Duration of } \\
\text { intervention: } 2 \text { years. }\end{array}$ & $\begin{array}{l}\text { Change in cognition } \\
\text { (NTB) }\end{array}$ & $\begin{array}{l}\text { z-score change: }+0.20 \text { in } \\
\text { intervention vs }+0.16 \\
\text { in controls. }{ }^{20} \text { Between- } \\
\text { group difference: } z= \\
0.022 / y r(P=0.03) .{ }^{20}\end{array}$ & $\begin{array}{l}\text { In } 362 \text { APOE } \varepsilon 4 \text { carriers, } \\
\text { the effect of } \\
\text { intervention was } \\
\text { significant for } 2 \text { of } 5 \\
\text { cognitive outcomes } \\
\text { (NTB and abbreviated } \\
\text { memory). }{ }^{26} \text { In } 747 \\
\text { APOE } \varepsilon 4 \text { non carriers, } \\
\text { the effect of } \\
\text { intervention was not } \\
\text { significant. }{ }^{26}\end{array}$ \\
\hline $\mathrm{MAPT}^{23}$ & $\begin{array}{l}N=1,680, \text { age } 70+, \\
\text { MMSE } 24+, \text { no } \\
\text { limitation of BADL, at } \\
\text { least one among: } \\
\text { memory complaint, } \\
\text { limitation in IADL, } \\
\text { slowness of gait }\end{array}$ & $\begin{array}{l}\text { Randomized, single-blind. } \\
\text { Interventions: (i) } \\
\text { multidomain } \\
\text { intervention plus } \\
\text { placebo, (ii) PUFA, (iii) } \\
\text { multidomain } \\
\text { intervention plus } \\
\text { PUFA. } \\
\text { Control: placebo alone. } \\
\text { Duration of } \\
\text { intervention: } 3 \text { years. }\end{array}$ & $\begin{array}{l}\text { Change in cognition } \\
\text { (composite measure) }\end{array}$ & $\begin{array}{l}\text { z-score change: }+0.024 \text { in } \\
\text { (iii) vs }-0.069 \text { in } \\
\text { controls } \\
\text { Between-group } \\
\text { difference: } z=0.09 \\
(P=0.14)\end{array}$ & $\begin{array}{l}\text { Impact of (iii): } \\
\text { In those with CAIDE } \\
\text { score } \geq 6 \text { vs }<6 \text { : } z \text {-score } \\
0.131 \text { vs }-0.201 \\
(P=0.023) ; \\
\text { In amyloid PET positive } \\
\text { vs negative: } z=0.708 \\
\text { vs }-0.075(P<0.001)\end{array}$ \\
\hline preDIVA $^{24}$ & $\begin{array}{l}N=3,454, \text { age } 70-78, \text { no } \\
\text { dementia }\end{array}$ & $\begin{array}{l}\text { Randomized, open-label. } \\
\text { Intervention: } \\
\text { nurse-led, multidomain } \\
\text { cardiovascular } \\
\text { intervention. } \\
\text { Control: usual care. } \\
\text { Duration of } \\
\text { intervention: } 6 \text { years. }\end{array}$ & $\begin{array}{l}\text { i) Incidence of dementia } \\
\text { ii) Decline of daily } \\
\text { function (ALDS score) }\end{array}$ & $\begin{array}{l}\text { i) } 6.5 \% \text { in intervention vs } \\
7.0 \% \text { in controls } \\
(P=0.54) \text {. } \\
\text { ii) } 85.7 \text { in intervention } \\
\text { vs } 85.7 \text { in controls } \\
(P=0.93) .\end{array}$ & $\begin{array}{l}\text { In those } 983 \text { with } \\
\text { untreated } \\
\text { hypertension and } \\
\text { adherent to treatment: } \\
\text { dementia incidence } \\
4.3 \% \text { vs } 7.4 \% \text { in } \\
\text { intervention and co } \\
\text { ntrol groups ( } P=0.02 \text { ). } \\
\text { In those with no history } \\
\text { of cardiovascular } \\
\text { disease: dementia } \\
\text { incidence } 5 \% \text { vs } 7 \% \text { in } \\
\text { intervention and } \\
\text { control groups } \\
\text { ( } P=0.02 \text { ). }\end{array}$ \\
\hline Look AHEAD 25 & $\begin{array}{l}N=1,091, \text { age } 45-76, \\
\text { overweight or obese } \\
\text { and with type } 2 \\
\text { diabetes }\end{array}$ & $\begin{array}{l}\text { Randomized, open label } \\
\text { Intervention: intensive } \\
\text { lifestyle intervention } \\
\text { (diet modification and } \\
\text { physical activity) } \\
\text { yielding long-term } \\
\text { weight loss. } \\
\text { Control: support and } \\
\text { education. } \\
\text { Duration: } 10 \text { years. }\end{array}$ & $\begin{array}{l}\text { Change in cognition } \\
\text { (composite measure) }\end{array}$ & $\begin{array}{l}\text { z-score change: } \\
\text {-0.073/year in } \\
\text { intervention vs } \\
-0.059 / \text { year in controls } \\
(P=0.068) \text {. }\end{array}$ & None \\
\hline
\end{tabular}

\footnotetext{
Interventions on

general

cardiovascular

risk reduction
} 
THE JOURNAL OF THE ALZHEIMER'S ASSOCIATION

TABLE 1 (Continued)

\begin{tabular}{|c|c|c|c|c|c|}
\hline Trial & Population & Study design & Primary outcome & Results & Exploratory analyses \\
\hline SPRINT MIND 27 & $\begin{array}{l}N=8,563, \text { age } 50+, \text { SBP } \\
130 \text { to } 180 \mathrm{mmHg} \text {, no } \\
\text { dementia }\end{array}$ & $\begin{array}{l}\text { Randomized, open-label } \\
\text { Intervention: intensive } \\
\text { SBP control (<120 } \\
\mathrm{mmHg} \text { ). } \\
\text { Control: standard SBP } \\
\text { control (<140 } \mathrm{mmHg} \text { ). } \\
\text { Duration of } \\
\text { intervention: } 3 \text { years. }\end{array}$ & Incidence of dementia & $\begin{array}{l}7.2 \text { cases per } 1000 \text { p-y in } \\
\text { treated vs } 8.6 \text { in } \\
\text { controls }(P=0.10)\end{array}$ & $\begin{array}{l}\text { Incidence of mild } \\
\text { cognitive impairment: } \\
14.6 \text { vs } 18.3 \text { cases per } \\
1000 \text { p-y in } \\
\text { intervention and } \\
\text { control groups } \\
(P=0.007) \text {. } \\
\text { Incidence of the } \\
\text { composite outcome of } \\
\text { mild cognitive } \\
\text { impairment or } \\
\text { probable dementia: } \\
20.2 \text { vs } 24.1 \text { cases per } \\
1000 \text { p-y in } \\
\text { intervention and } \\
\text { control group } \\
(P=0.01) \text {. }\end{array}$ \\
\hline Zhang et al. ${ }^{22}$ & $\begin{array}{l}N=732, \text { age } 60+, \text { with } \\
\text { hypertension treated } \\
\text { with } \\
\text { hydrochlorothiazide }\end{array}$ & $\begin{array}{l}\text { Randomized, } \\
\text { double-blind } \\
\text { Interventions: (i) } \\
\text { telmisartan (ii) } \\
\text { low-dose rosuvastatin. } \\
\text { Control: placebo. } \\
\text { Duration: } 60 \text { months. }\end{array}$ & $\begin{array}{l}\text { (i) Change in cognition } \\
\text { (MMSE and DRS) } \\
\text { (ii) Incidence of } \\
\text { cognitive impairment } \\
\text { (composite of MMSE } \\
\text { and DRS) }\end{array}$ & $\begin{array}{l}\text { (i) MMSE change: }-1.2 \text { in } \\
\text { rosuvastatin vs }-1.7 \text { in } \\
\text { controls }(P<0.001) \text {. } \\
\text { DRS change: }-3.1 \text { in } \\
\text { rosuvastatin vs }-4.4 \text { in } \\
\text { controls }(P=0.029) \text {. } \\
\text { (ii) } 19 \% \text { in rosuvastatin } \\
\text { vs } 11 \% \text { in controls } \\
(P=0.002) \text {. }\end{array}$ & None \\
\hline LIFE $^{21}$ & $N=1,298$, age $70-89$ & $\begin{array}{l}\text { Randomized, single-blind } \\
\text { Intervention: physical } \\
\text { activity (150 min/week } \\
\text { of walking + strength, } \\
\text { flexibility, and balance } \\
\text { training). } \\
\text { Control: health } \\
\text { education program. } \\
\text { Duration: } 2 \text { years. }\end{array}$ & $\begin{array}{l}\text { Cognitive frailty } \\
\text { (composite ordinal } \\
\text { variable) }\end{array}$ & $\begin{array}{l}21 \% \text { reduction of risk of } \\
\text { worsening in } \\
\text { intervention vs } \\
\text { controls }(P=0.032) \text {. }\end{array}$ & None \\
\hline
\end{tabular}

Abbreviations: ALDS, academic medical center linear disability score; BADL, basic activities of daily living; CAIDE, cardiovascular risk factors, aging, and incidence of dementia; DRS, Mattis dementia rating scale; HR, hazard ratio; FINGER, Finnish Geriatric Intervention Study to Prevent Cognitive Impairment and Disability; IADL, Instrumental Activities of Daily Living; MAPT, Multidomain Alzheimer Preventive Trial; MMSE, mini-mental state examination; LIFE, Lifestyle Interventions and Independence for Elders; NTB, neuropsychological test battery; PUFA, polyunsaturated fatty acids; SBP, systolic blood pressure.

cognitive domains was greater than that of the control intervention in apolipoprotein $\mathrm{E}$ (APOE) $\varepsilon 4$ carriers but not in non-carriers. ${ }^{26}$ In MAPT, the effect of the intervention was more beneficial in the participants with elevated Cardiovascular Risk Factors, Aging, and Incidence of Dementia (CAIDE) risk score or with positive amyloid positron emission tomography (PET) but not in those with low CAIDE risk score or negative amyloid $\mathrm{PET}^{23}$ (Table 1 and Figure 3). SPRINT MIND showed a significant reduction of incident mild cognitive impairment $(\mathrm{MCl}$; and in the composite outcome of $\mathrm{MCl}$ or probable dementia) cases in the group treated with a more "aggressive" antihypertensive strategy, ${ }^{27}$ consistent with a previous clinical trial showing that low-dose statins reduce cognitive decline in patients with hypertension. ${ }^{22}$ While other studies have shown the potential danger to the brain of too-low blood pressure, ${ }^{28}$ it will be critical to identify patients who can benefit from aggressive blood pressure control from those for whom it will be detrimental based on individual features (eg, by taking age into account).
This points the way toward a precision prevention approach in dementia risk reduction, in which preventive interventions can be concentrated on higher risk individuals more likely to benefit, sparing time, money, and side effects to the others.

While we believe that the results of the above studies outline a suggestive and consistent pattern of dementia risk reduction following lifestyle interventions and aggressive vascular risk factor management, we acknowledge that they all have methodological limitations, among which is the choice of the primary endpoint. Indeed, an optimal endpoint should be relevant to patients and sensitive enough to detect any change due to the intervention. For example, changes in cognition are more sensitive to interventions than changes in dementia incidence, but their implications are only marginal (especially if an improvement in cognition is observed also in the control group). On the other hand, reduction in dementia incidence has a strong impact on patients and society but might require a larger group size and longer follow-up 
FINGER

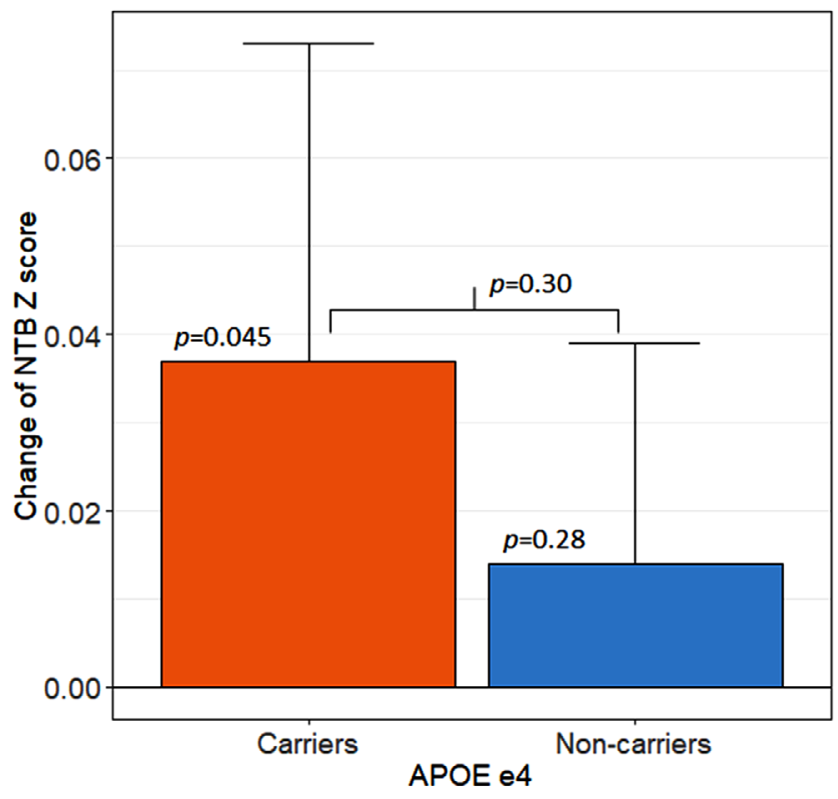

MAPT

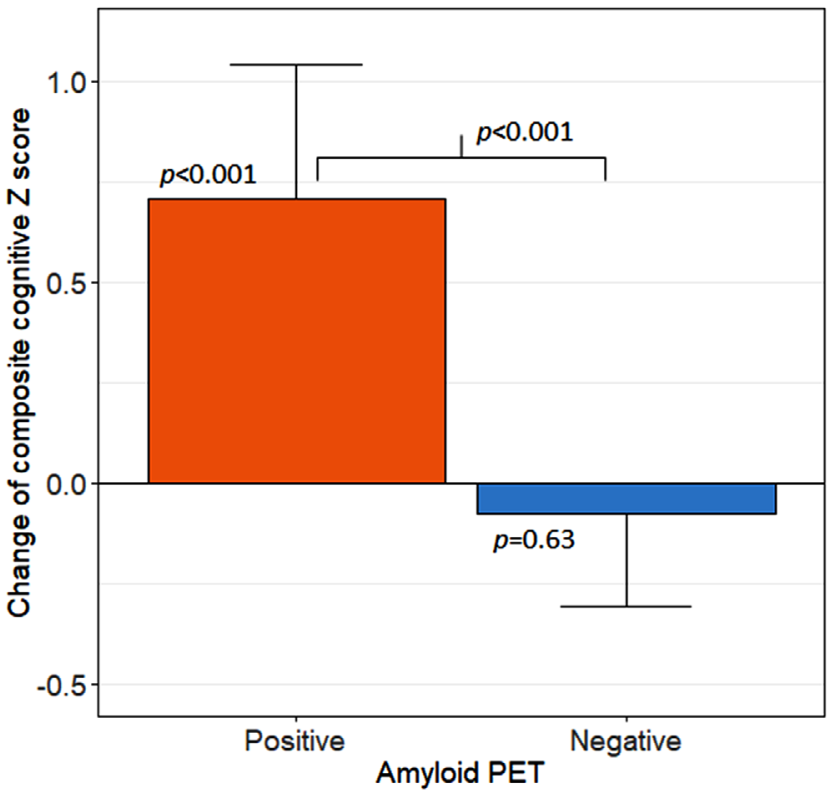

FIG URE 3 Evidence supporting the efficacy of multidomain interventions on cognitive performance in genetically and molecularly defined subgroups of participants at increased risk for dementia. Values are differences between the mean changes in intervention versus control groups (after 1 year in 1109 participants to the Finnish Geriatric Intervention Study to Prevent Cognitive Impairment and Disability [FINGER], ${ }^{20}$ and after 3 years in 72 participants to the Multidomain Alzheimer Preventive Trial [MAPT] ${ }^{23}$ study). A positive value reflects a greater effect of the experimental intervention, whereas a negative value of the control intervention (see also Table 1). The effect of intervention was significant in FINGER apolipoprotein E (APOE) $\varepsilon 4$ carriers and MAPT amyloid-positive participants, but not in FINGER APOE $\varepsilon 4$ non-carriers nor MAPT amyloid-negative participants. The interaction of intervention by APOE $\varepsilon 4$ carrier status in FINGER was not statistically significant, while amyloid positivity in MAPT was significant. Bars represent 95\% confidence intervals. NTB: neuropsychological test battery

to be detected. Moreover, the implementation of a precision prevention approach requires the identification of a specific target population (eg, based on APOE genotype, and vascular and lifestyle risk factors). Finally, while changing lifestyles in adults and older persons is already a significant challenge, maintaining healthy behaviors will be an even more challenging endeavor. Specifically, the FINGER and MAPT studies showed that participants' compliance to the intervention decreased with increasing complexity, and that some factors can enhance adherence (eg, face-to-face contact). ${ }^{29}$ Moreover, health-care professionals will play a key role in this context. These are only some issues related to the study design of prevention trials, and future prospective randomized interventions-which are still strongly needed-should take them into account.

\subsection{Synergies between current programs on vascular risk reduction and future programs on dementia}

In 2011, a statement of the American Heart Association (AHA) on the contribution of cardiovascular risk factors to vascular cognitive impairment and $A D$ dementia emphasized communalities that can be developed to improve the benefit of prevention programs. ${ }^{30}$ More recently, the AHA recognized "optimal brain health" as the "foundation for a new strategic direction going forward in cardiovascular health promo- tion and disease prevention." ${ }^{31}$ The opportunity for synergies between dementia prevention and cardiovascular prevention programs is obvious.

Cardiovascular disease prevention programs are ongoing in most industrialized countries, usually established by national health organizations, such as the National Health Service in the UK and the AHA in the United States. The experience gained in more than 50 years of cardiovascular prevention programs as well as some conceptual analogies and practical overlaps can be used today in the planning of dementia prevention action plans (Table 2). Dementia prevention programs may more generally benefit from the experience and infrastructure of cardiovascular action plans that may run on a statewide scale, with comparable target population and at a lower cost.

A risk of integrating dementia with cardiovascular prevention programs is to blur the information that the patient receives. In persons with low health literacy and initial cognitive impairment, this might raise confusion and adversely affect compliance to prevention interventions. Information delivered to the population on cardiovascular health via television, newspaper advertisements, and general practitioners will need to be re-tuned to include clear and unequivocal dementia-specific messages. The involvement of current memory clinics in educational programs will ensure harmonization to the latest scientific advancements. While using "dementia prevention" as the hook to modify behavior in, for example, mid-life may be unlikely to prove relevant to people so many years from dementia onset, catching 
THE JOURNAL OF THE ALZHEIMER'S ASSOCIATION

TA B LE 2 Analogies between prevention targets for coronary heart disease and Alzheimer's disease

\begin{tabular}{|c|c|c|c|}
\hline & & Primary prevention & Secondary prevention \\
\hline \multirow[t]{2}{*}{ Pathophysiology } & $\begin{array}{l}\text { Coronary heart } \\
\text { disease }\end{array}$ & $\begin{array}{l}\text { Induction: interaction between genetic and traditional } \\
\text { modifiable risk factors (eg, hypercholesterolemia, } \\
\text { hypertension, diabetes) leading to inflammation of } \\
\text { the artery wall. }\end{array}$ & Latency: atherosclerosis \\
\hline & Alzheimer's disease & $\begin{array}{l}\text { Induction: interaction between genetic factors and } \\
\text { environmental exposures to promote } \mathrm{A} \beta 42 \\
\text { aggregation and tau phosphorylation. }\end{array}$ & $\begin{array}{l}\text { Deposition of } \mathrm{A} \beta 42 \text { in cortical plaques } \\
\text { and/or deposition of } \\
\text { hyper-phosphorylated tau in } \\
\text { neurofibrillary tangles. }\end{array}$ \\
\hline \multirow[t]{2}{*}{ Target population } & $\begin{array}{l}\text { Coronary heart } \\
\text { disease }\end{array}$ & $\begin{array}{l}\text { Myocardial infarction-free and atherosclerosis-free } \\
\text { patients. }\end{array}$ & $\begin{array}{l}\text { High-risk persons (older age, multiple } \\
\text { cardiovascular risk factors) }\end{array}$ \\
\hline & Alzheimer's disease & $\begin{array}{l}\text { Cognitively normal persons at high risk (APOE } \varepsilon 4 \\
\text { carriers, family history) who are amyloid and/or tau } \\
\text { negative, and neurodegeneration negative. }\end{array}$ & $\begin{array}{l}\text { Cognitively normal persons who are } \\
\text { amyloid and/or tau positive. }\end{array}$ \\
\hline $\begin{array}{l}\text { Detection and } \\
\text { intervention }\end{array}$ & Alzheimer's disease & $\begin{array}{l}\text { Screening for vascular and dementia-specific risk } \\
\text { factors (hearing loss, depression, social isolation). } \\
\text { Interventions on non-pathophysiologic and specific } \\
\text { risk factors. Interventions to increase resilience to } \\
\text { pathology (eg, specific nutrients). }\end{array}$ & $\begin{array}{l}\text { Detection of brain amyloidosis and brain } \\
\text { tauopathy. Amyloid and tau lowering } \\
\text { agents to prevent cognitive impairment. } \\
\text { Interventions to increase resistance to } \\
\text { pathology. }\end{array}$ \\
\hline
\end{tabular}

message tags such as the one recently suggested by the European Academy of Neurology might be instrumental ("what is good for the heart is good for the brain"). 32

\section{5 | SECONDARY PREVENTION WITH DISEASE MODIFYING THERAPIES IN COGNITIVELY NORMAL PERSONS WITH AD PATHOLOGY}

The failure of DMT trials on patients with $\mathrm{MCl}$ or dementia does not invalidate amyloid as a treatment target. Current DMT trials implicitly assume that amyloid is a deterministic cause of neurodegeneration in the context of the amyloid cascade hypothesis (Figure 2). However, if brain amyloid is rather a probabilistic risk factor, removing brain amyloid when neurodegeneration is already established (as is the case of mild to moderate AD dementia) is unlikely to affect it, as well as, by analogy, treating hypercholesterolemia in patients with stroke may only marginally alter its natural history. In the probabilistic risk factor scenario, prevention should take place when neurodegeneration is absent or very mild. Indeed, trials have been designed and implemented in $\mathrm{CN}$ persons at high risk of incident cognitive impairment and dementia due to AD pathology. In 2019, there were six DMTs in phase III trials on $\mathrm{CN}$ participants, ${ }^{3}$ and their results are eagerly awaited. However, if hopes for efficacy are fulfilled, clinical and logistic challenges will be paramount.

More persons now seek advice in memory clinics complaining of declining cognitive performance although scoring normal on formal cognitive testing ("subjective cognitive decline"). Others do not report cognitive problems and are just worried about future cognitive decline due to family history, or simply concerned about preserving their memory and general cognitive abilities (sometimes referred to as "worried well" patients). This group of patients is enriched with some high-risk individuals ${ }^{33}$ and accounts for $20 \%$ to $30 \%{ }^{34,35}$ of all new patients seeking help in memory clinics. The availability of DMTs will inevitably lead to more of these individuals seeking medical advice.

Current memory clinics are designed for the biopsychosocial needs of people with cognitive impairment and variable degrees of functional limitation that are likely to lead to a diagnosis of dementia but were never designed and are ill-equipped to deal with this new population of patients presenting with different concerns, requests, expectations, and hopes.

A new generation of brain health services (variably referred to as dementia prevention services, brain health clinics, dementia prevention clinics, etc.) is being developed along with specific expertise, working tools, and organizational models. Early pilot experiences of brain health services, so far in the research and development stage, are ongoing in Barcelona, Edinburgh, Cologne, and Geneva. To a greater or lesser degree, they adhere to three guiding principles: (1) risk profiling, (2) risk communication, and (3) implementation of personalized prevention plans. Their current health offer targets non-demented persons $(\mathrm{CN}$ and $\mathrm{MCl})$ and includes a personalized approach of disclosing dementia risk estimates and precision risk control programs in the context of phase II and III clinical trials of experimental DMTs. This approach is a paradigm shift from the current diagnostic approach in memory clinics, where, for example, APOE genotyping is not recommended exactly for the reason that, being a risk factor, its diagnostic sensitivity and specificity are relatively poor. ${ }^{36}$ Indeed, pilot evidence suggests that APOE genotyping might be a critical variable in 
the context of brain health services to estimate the personalized risk for dementia (Figure 2) and because it was shown to mediate the effect of risk reduction interventions (subgroups analysis of the FINGER trial [see Figure 3], in which the effect of intervention was significant in APOE $\varepsilon 4$ carriers but not in non-carriers). However, further research and ad hoc clinical trials selecting the target population based on APOE genotype are needed to prove and support its potential utility, and eventually recommend APOE testing in brain health services. The approach has also been expressed clearly in the UK-led Edinburgh Consensus on preparing for the advent of disease-modifying therapies for $A D$, which envisaged the establishment of new brain health services to complement existing memory clinics. In brain health services, disease detection, risk profiling, and prevention of dementia would be the overriding objective. ${ }^{37}$ However, a number of challenges will need to be met before the health offer of these and similar brain health services can enter the production stage (Table 3).

The first challenge will be efficient screening of persons at high risk. Performing amyloid PET, tau PET, and lumbar puncture in all persons would clearly be prohibitively expensive. Advances in blood-based biomarkers of amyloidosis, ${ }^{38}$ tauopathy, ${ }^{39}$ and neurodegeneration ${ }^{40}$ promise to be of great value, and others based on retinal imaging and saliva are being studied. If peripheral biomarkers prove to be reliable and effective, a large-scale screening for neurodegenerative diseases will be possible and the general population will be reached, ${ }^{41}$ and those at risk for dementia (ie, biomarker positive) will ultimately be addressed to brain health services. Large longitudinal studies will be needed to accurately estimate the effect on screening efficiency of key risk modifiers such as age, family history, and APOE genotype. To accurately estimate the risk for AD dementia of those screening positive, large population-based studies including imaging and cerebrospinal fluid biomarkers, genetics, and accounting for "traditional" risk factors will be required. In due course, protocols that can be delivered at scale, cost, and with a high degree of precision will be developed.

Risk communication will be burdened with the known challenges of communicating the very concept of risk to the general public. New tools, protocols, and skills for structured risk disclosure will be needed, such as the one developed by the A4 trial for amyloid PET. ${ }^{42}$ Special attention will need to be devoted to matching messaging and disclosure to people from a variety of cultural, socio-economic, and societal backgrounds where belief systems and expectations may vary substantially.

In the clinical pipeline of brain health services, risk profiling and communications will be followed by individualized risk-reduction interventions (aka personalized prevention plans). Lifestyle and pharmacologic interventions may be prioritized based on the individual cumulative risk of dementia (so-called risk-stratified care management), analogous to what is currently done for the treatment of hypertension, diabetes, and hypercholesterolemia. In times when effective interventions directed to pathophysiological risk factors are lacking, high-risk, pathophysiological-biomarker-positive persons will be referred to prevention clinical trials with putative DMT (eg, via registries ${ }^{43}$ ). In these
TABLE 3 Preparatory actions in view of establishing and running brain health services

\begin{tabular}{|c|c|}
\hline Screening & $\begin{array}{l}\text { Finalizing analytical validation and carrying out } \\
\text { clinical validation of blood-based and other } \\
\text { peripheral biomarkers. } \\
\text { Estimating the effect of age, family history, } \\
\text { and APOE on false positive and negative } \\
\text { rates of biomarkers. }\end{array}$ \\
\hline Risk profiling & $\begin{array}{l}\text { Estimating the risk of imaging and CSF } \\
\text { biomarkers adjusted for communality with } \\
\text { APOE and traditional risk factors. } \\
\text { Developing user-friendly and cost-effective } \\
\text { risk estimate protocols for the economic and } \\
\text { efficient use of second line expensive or } \\
\text { specialized diagnostic workup resources } \\
\text { (amyloid and tau PET, lumbar puncture, FDG } \\
\text { PET, etc.). }\end{array}$ \\
\hline $\begin{array}{l}\text { Risk } \\
\text { communication }\end{array}$ & $\begin{array}{l}\text { Developing tools, protocols, and skills for the } \\
\text { effective communication of risk. } \\
\text { Adjusting the above for effective and efficient } \\
\text { communication to persons with widely } \\
\text { different educational background. }\end{array}$ \\
\hline Interventions & $\begin{array}{l}\text { Prioritize lifestyle and pharmacologic } \\
\text { interventions based on individual cumulative } \\
\text { risk level. } \\
\text { Customize based on genetic profile or other } \\
\text { biological feature (precision medicine } \\
\text { interventions). } \\
\text { Modulate based on age, gender, education, } \\
\text { and individual preferences. } \\
\text { Developing and testing innovative } \\
\text { pharmacologic and non-pharmacologic } \\
\text { interventions (eg, web-based). }\end{array}$ \\
\hline Education & $\begin{array}{l}\text { Integrating brain health services with:- } \\
\text { awareness campaigns on brain health for the } \\
\text { general population } \\
\text { - other prevention programs in general } \\
\text { practice (mainly in the vascular prevention } \\
\text { area) } \\
\text { - treatment and education in memory clinics. }\end{array}$ \\
\hline Organization & $\begin{array}{l}\text { Developing financially sustainable business } \\
\text { models. } \\
\text { Developing registries for subjects at risk for } \\
\text { inclusion in intervention studies }\end{array}$ \\
\hline Ethics & $\begin{array}{l}\text { Ensuring right to know and not to know for all } \\
\text { persons. } \\
\text { Ensuring informative and respectful } \\
\text { communication of risk to persons (with } \\
\text { particular attention to those with low } \\
\text { educational background). } \\
\text { Data and knowledge protection. } \\
\text { Ensuring the confidentiality of risk } \\
\text { assessment versus insurers depending on } \\
\text { local regulations. }\end{array}$ \\
\hline
\end{tabular}

Abbreviations: APOE, apolipoprotein E; FDG PET, fluorodeoxyglucosepositron emission tomography; CSF, cerebrospinal fluid; $P E T$, positron emission tomography 
patients, the uncertainty of treatment group allocation (active drug or placebo) and drug effectiveness may suggest a proactive approach to mid-life and late-life risk factors. Prioritization will inevitably need revision as/when effective disease modifiers are available.

Already available clinical trial results (eg, FINGER and MAPT) suggest that preventive interventions will be customized based on genetic profile (ie, APOE) or other biological feature (precision medicine interventions). Future trials will need to estimate the impact of demographic and clinical modulators of response such as age, gender, education, associated anxiety and depression, personality profile, and personal preferences. Observational and interventional studies indicate that starting interventions in middle rather than late life may have better results and life-course perspective. ${ }^{44}$ Informatics platforms ${ }^{45}$ may be embedded in a large network of brain health services for perpetual risk model refinement especially benefiting from machine learning approaches where dementia onset may be the originating ground truth to be replaced by alternate and more relevant ground truths, which are disease markers or features noticeable earlier in the course of the disease.

Innovative and possibly cost-effective lifestyle programs that can be implemented leveraging group training and modern technology (eg, web-based apps ${ }^{46}$ ) may be used to promote self-management, or can also be partially integrated to existing prevention programs of other chronic diseases such as cardiovascular diseases, stroke, and diabetes given that these disorders share several common risk factors. Non-conventional preventive interventions targeting more innovative pathophysiological hypotheses of neurodegeneration may in due course be integrated into brain health services once shown effective; such approaches might include novel drugs, behavioral modifications, neurostimulation, and nutritional principles. ${ }^{47,48}$

Ethical issues will arise that require being specifically addressed such as ensuring informative and respectful communication of risk and ensuring that disclosure of risk does not have adverse consequences, for example, for insurance. Educational activities will need to be set up in the general population, general medical practices, and current memory clinics. The financially sustainable business model that will be uptaken for brain health services will largely depend on the availability of approved new drugs. Registries for subjects at very high risk will allow us to set up a point-of-care registry system to ensure coordination of care. ${ }^{49}$ Finally, the research community should strictly recommend the adoption of rigorous methods and the implementation of evidence-based prevention plans only. At the same time, the research community should be able to educate the general population and therefore avoid the proliferation of pseudo-medicine services ${ }^{5,50}$ taking advantage of people's concerns.

\section{6 | CONCLUSIONS}

Dementia and neurodegenerative diseases research and care is in a dynamic state of evolution and in need of increased synergy among public health, general practice, and specialist care. Independent of the availability of DMTs, precision dementia prevention and personalized care should liaise with resources in the vascular prevention field in public health programs and in general practice. If disease modifiers prove effective to delay adverse outcomes in $\mathrm{CN}$ persons, a new model of brain health services may need to be developed, which will encounter a number of novel clinical, ethical, and organizational challenges.

While much evidence still needs to be collected before scientifically sound brain health services can be launched in production mode, we believe that it is urgent to set up research brain health services that may pilot the model and start designing and testing the weapons that society needs in order to fight the battle against the rising dementia prevalence.

\section{ACKNOWLEDGMENTS}

GBF, JLM, FB, JD, MK, AN, WvdF, BV, FJ, PS, and CR receive funding by the European Prevention of Alzheimer's Dementia consortium (EPAD, grant agreement number: 115736) and Amyloid imaging to prevent Alzheimer's disease (AMYPAD, grant agreement number: 115952). JS is funded only by AMYPAD. FB is supported by the NIHR biomedical research center at UCLH. WF, and PS receive funding from Joint Programming for Neurodegenerative Diseases (JPND-Euro-FINGERS, ZonMW \#733051102). WF receives funding via health-Holland, Top Sector Life Sciences \& Health (Personalized Prevention, grant no.: LSHM19051-H036).

\section{CONFLICTS OF INTEREST}

GBF reports grants from Alzheimer Forum Suisse, Académie Suisse des Sciences Médicales, Avid Radiopharmaceuticals, Biogen, GE International, Guerbert, Association Suisse pour la Recherche sur l'Alzheimer, IXICO, Merz Pharma, Nestlé, Novartis, Piramal, Roche, Siemens, Teva Pharmaceutical Industries, Vifor Pharma, and Alzheimer's Association; he has received personal fees from AstraZeneca, Avid Radiopharmaceuticals, Elan Pharmaceuticals, GE International, Lundbeck, Pfizer, and TauRx Therapeutics.

PS reports fees (paid to his institution) for serving as a principal investigator for EIP Pharma, Probiodrug, Roche, Merck, and the Dominantly Inherited Alzheimer Network Trials Unit (DIAN-TU); fees (paid to his institution) for consultancy from Axovant Sciences; and is chair of the executive committee of a program funded by Novartis relating to potential amyloid deposition or cognitive decline associated with sacubitril/valsartan.

WvdF reports grants from The Netherlands Organisation for Health Research and Development (ZonMW) Memorabel programme (ABIDE; project No 733050201), Stichting Gieskes-Strijbis Fonds (SCIENCe project), Stichting Life Sciences \& Health-Topconsortium voor Kennis en Innovatie (ABIDE-communication; project No LSHM16025); grants paid to her institution from Cardiovasculair Onderzoek Nederland, Biogen, Boehringer Ingelheim, Piramal Imaging, Alzheimer Nederland, Janssen Pharmaceutica (Stellar initiative), Combinostics, and Roche.

JLM reports grants from and has served as a principal investigator for Novartis, Roche, Merck, and Janssen Pharmaceutica; reports personal fees for consultancy from Axovant Sciences, Eli Lilly, Novartis, Roche, Roche Diagnostics, Merck, Merz Pharma, Biogen, Oryzon, and 
Lundbeck; reports personal fees for serving on a trial board for Genentech.

JS reports grants from the National Institute for Health Research University College London Hospitals Biomedical Research Centre, Wolfson Foundation, Engineering and Physical Sciences Research Council (grant number: EP/J020990/1), Medical Research Council Dementias Platform UK (grant number: MR/L023784/1), Alzheimer's Research UK (grant numbers: ARUK-Network 2012-6-ICE; ARUKPG2017-1946; ARUK-PG2017-1946), Brain Research UK (grant number: UCC14191), Weston Brain Institute (grant number: UB170045), European Union's Horizon 2020 research and innovation programme (grant number: 666992); reports grants and PET tracers from Avid Radiopharmaceuticals; personal fees for consultancy from Roche, Merck, and Biogen; personal fees for consultancy and speaker fees from Eli Lilly; royalties from Oxford University Press and Henry Stewart Talks; and serves on a Data Safety Monitoring Board for AXON Neuroscience SE.

FB reports grants from National Institute for Health Research University College London Hospitals Biomedical Research Centre, European Progression of Neurological Disease Initiative (EuroPOND; funded by Horizon 2020), the UK Multiple Sclerosis Society, the Dutch MS Society, PICTURE (IMDI-NWO), and ECTRIMS-MAGNIMS; reports personal fees for participating in a steering committee with Bayer Pharmaceuticals, reports personal fees for consultancy from and serves on a Data Safety Monitoring Board for Roche and GenzymeSanofi, reports personal fees for consultancy from Biogen, Teva Pharmaceutical Industries, Merck, Novartis, Janssen Pharmaceutica, IXICO, GeNeuro, Apitope, and Lundbeck.

$B D$ reports grants from and is a principal investigator for Boehringer Ingelheim, Eli Lilly, Biogen, Roche, Merck, Amoneta Diagnostics, Piramal, DIAN-TU; and personal fees for consultancy from BoehringerIngelheim, Biogen, Merck, and Eli Lilly.

FJ reports grants from and is a principal investigator for Eli Lilly, Biogen, EISAI, Roche, Novartis, Axovant and Boehringer; and personal fees for consultancy from Eli Lilly, Roche, Merck, Janssen Pharmaceutica, Biogen, and AC Immune.

CR reports grants from Biogen, Janssen Pharmaceutica, Merck, and Takeda; personal fees from Merck, Pfizer, Eisai, Actinogen, Kyowa Pharmaceutical, Eli Lilly, and Roche; and non-financial support from Janssen Pharmaceutica for work through the European Prevention of Alzheimer's Dementia Consortium.

All other authors declare no competing interests.

\section{AUTHOR CONTRIBUTIONS}

GBF and DA did the literature review. GBF drafted the first version of the Personal View. GBF, PS, FJ, CR, JLM, DA, and BV contributed to the original concept and revised the first version. All authors contributed to content and revisions.

\section{REFERENCES}

1. Serrano-Pozo A, Frosch MP, Masliah E, Hyman BT. Neuropathological alterations in Alzheimer disease. Cold Spring Harb Perspect Med. 2011;1(1):a006189-a006189.
2. Cummings JL. Treatment of Alzheimer's disease: the role of symptomatic agents in an era of disease-modifying therapies. Rev Neurol Dis. 2007;4(2):57-62.

3. Cummings J, Lee G, Ritter A, Sabbagh M, Zhong K. Alzheimer's disease drug development pipeline: 2019. Alzheimer's Dement Transl Res Clin Interv. 2019;5:272-293.

4. International D. World Alzheimer Report 2019: Attitudes to Dementia; World Alzheimer Report 2019: Attitudes to Dementia. www.daviddesigns. co.uk. Accessed October 23, 2019.

5. Frisoni GB, Ritchie C, Carrera E, et al. Re-aligning scientific and lay narratives of Alzheimer's disease. Lancet Neurol. 2019;18(10):918-919.

6. Langa KM. Is the risk of Alzheimer's disease and dementia declining? Alzheimers Res Ther. 2015;7(1):34.

7. Derby CA, Katz MJ, Lipton RB, Hall CB. Trends in dementia incidence in a birth cohort analysis of the Einstein Aging Study. JAMA Neurol. 2017;74(11):1345-1351.

8. Rocca WA, Petersen RC, Knopman DS, et al. Trends in the incidence and prevalence of Alzheimer's disease, dementia, and cognitive impairment in the United States. Alzheimer's Dement. 2011;7(1):80-93.

9. Satizabal CL, Beiser AS, Chouraki V, Chêne G, Dufouil C, Seshadri S. Incidence of dementia over three decades in the Framingham Heart Study. N Engl J Med. 2016;374(6):523-532.

10. Schrijvers EMC, Verhaaren BFJ, Koudstaal PJ, Hofman A, Ikram MA, Breteler MMB. Is dementia incidence declining? Trends in dementia incidence since 1990 in the Rotterdam Study. Neurology. 2012;78(19):1456-1463.

11. Prince M, Ali G-C, Guerchet M, Prina AM, Albanese E, Wu Y-T. Recent global trends in the prevalence and incidence of dementia, and survival with dementia. Alzheimers Res Ther. 2016;8(1):23.

12. Matthews FE, Stephan BCM, Robinson L, et al. A two decade dementia incidence comparison from the Cognitive Function and Ageing Studies I and II. Nat Commun. 2016;7(1):11398.

13. Kovari E, Herrmann FR, Bouras C, Gold G. Amyloid deposition is decreasing in aging brains: an autopsy study of 1,599 older people. Neurology. 2014;82(4):326-331.

14. Savva GM, Wharton SB, Ince PG, et al. Age, neuropathology, and dementia. N Engl J Med. 2009;360(22):2302-2309.

15. Dubois B, Hampel H, Feldman HH, et al. Preclinical Alzheimer's disease: definition, natural history, and diagnostic criteria. Alzheimer's Dement. 2016;12(3):292-323.

16. Jack CR, Bennett DA, Blennow K, et al. NIA-AA Research Framework: toward a biological definition of Alzheimer's disease. Alzheimers Dement. 2018;14(4):535-562.

17. Livingston G, Sommerlad A, Orgeta V, et al. Dementia prevention, intervention, and care. Lancet Commissions. 2017;390(10113):26732734.

18. Risk Reduction of Cognitive Decline and Dementia - WHO Guidelines. https://apps.who.int/iris/bitstream/handle/10665/312180/ 9789241550543-eng.pdf?ua=1. Accessed October 23, 2019.

19. Kivipelto M, Mangialasche F, Ngandu T. Lifestyle interventions to prevent cognitive impairment, dementia and Alzheimer disease. Nat Rev Neurol. 2018;14(11):653-666.

20. Ngandu T, Lehtisalo J, Solomon A, et al. A 2 year multidomain intervention of diet, exercise, cognitive training, and vascular risk monitoring versus control to prevent cognitive decline in at-risk elderly people (FINGER): a randomised controlled trial. Lancet. 2015;385(9984):2255-2263.

21. Liu Z, Hsu F-C, Trombetti A, et al. Effect of 24-month physical activity on cognitive frailty and the role of inflammation: the LIFE randomized clinical trial. BMC Med. 2018;16(1):185.

22. Zhang H, Cui Y, Zhao Y, et al. Effects of sartans and low-dose statins on cerebral white matter hyperintensities and cognitive function in older patients with hypertension: a randomized, double-blind and placebocontrolled clinical trial. Hypertens Res. 2019;42(5):717-729. 
23. Andrieu S, Guyonnet S, Coley N, et al. Effect of long-term omega 3 polyunsaturated fatty acid supplementation with or without multidomain intervention on cognitive function in elderly adults with memory complaints (MAPT): a randomised, placebo-controlled trial. Lancet Neurol. 2017;16(5):377-389.

24. van Charante EPM, Richard E, Eurelings LS, et al. Effectiveness of a 6-year multidomain vascular care intervention to prevent dementia (preDIVA): a cluster-randomised controlled trial. Lancet. 2016;388(10046):797-805.

25. Espeland MA, Carmichael O, Hayden K, et al. Long-term impact of weight loss intervention on changes in cognitive function: exploratory analyses from the action for health in diabetes randomized controlled clinical trial. J Gerontol A Biol Sci Med Sci. 2018;73(4):484-491.

26. Solomon A, Turunen H, Ngandu T, et al. Effect of the apolipoprotein $E$ genotype on cognitive change during a multidomain lifestyle intervention. JAMA Neurol. 2018.

27. Williamson JD, Pajewski NM, Auchus AP, et al. Effect of intensive vs standard blood pressure control on probable dementia. JAMA 2019;321(6):553.

28. Duschek S, Schandry R. Reduced brain perfusion and cognitive performance due to constitutional hypotension. Clin Auton Res. 2007;17(2):69-76.

29. Coley N, Ngandu T, Lehtisalo J, et al. Adherence to multidomain interventions for dementia prevention: data from the FINGER and MAPT trials. Alzheimer's Dement. 2019;15(6):729-741.

30. Gorelick PB, Scuteri A, Black SE, et al. Vascular contributions to cognitive impairment and dementia. Stroke. 2011;42(9):2672-2713.

31. Gorelick PB, Furie KL, ladecola C, et al. Defining optimal brain health in adults: a presidential advisory from the American Heart Association/American Stroke Association. Stroke. 2017;48(10): e284-e303.

32. Giovannoni G, Noyce AJ, Scheltens P, et al. Time Matters - A Call to Prioritize Brain Health; 2019. http://www.oxfordhealthpolicyforum.org/ reports/brain-diseases/brain-diseases-report

33. Slot RER, Sikkes SAM, Berkhof J, et al. Subjective cognitive decline and rates of incident Alzheimer's disease and non-Alzheimer's disease dementia. Alzheimers Dement. 2019;15(3):465-476.

34. van der Flier WM, Pijnenburg YAL, Prins N, et al. Optimizing patient care and research: the Amsterdam Dementia Cohort. J Alzheimers Dis. 2014;41(1):313-327.

35. Hejl A, Høgh P, Waldemar G. Potentially reversible conditions in 1000 consecutive memory clinic patients. J Neurol Neurosurg Psychiatry. 2002;73(4):390-394.

36. Farrer LA, Brin MF, Elsas L, et al. Statement on use of apolipoprotein E testing for Alzheimer disease. JAMA. 1995;274(20):1627 1629.

37. Ritchie CW, Russ TC, Banerjee S, et al. The Edinburgh Consensus: preparing for the advent of disease-modifying therapies for Alzheimer's disease. Alzheimers Res Ther. 2017;9(1):85.

38. Verberk IMW, Slot RE, Verfaillie SCJ, et al. Plasma amyloid as prescreener for the earliest Alzheimer pathological changes. Ann Neurol. 2018;84(5):648-658.
39. Mattsson $\mathrm{N}$, Zetterberg $\mathrm{H}$, Janelidze $\mathrm{S}$, et al. Plasma tau in Alzheimer disease. Neurology. 2016;87(17):1827-1835.

40. Mattsson N, Cullen NC, Andreasson U, Zetterberg H, Blennow K. Association between longitudinal plasma neurofilament light and neurodegeneration in patients with Alzheimer disease. JAMA Neurol. 2019;76(7):791.

41. Ribaldi F, Altomare D, Frisoni GB. Comment: is a large-scale screening for Alzheimer's disease possible? Yes, in a few years. J Prev Alzheimer's Dis. 2019;6(4):221-222.

42. Mozersky J, Sankar P, Harkins K, Hachey S, Karlawish J. Comprehension of an elevated amyloid positron emission tomography biomarker result by cognitively normal older adults. JAMA Neurol. 2017.

43. Hersenonderzoek. https://hersenonderzoek.nl/. Accessed January 3 , 2018.

44. Solomon A, Mangialasche F, Richard E, et al. Advances in the prevention of Alzheimer's disease and dementia. J Intern Med. 2014;275(3):229-250.

45. Draganski B, Kherif F, Damian D, Demonet J-F, MemoNet consortium. A nation-wide initiative for brain imaging and clinical phenotype data federation in Swiss university memory centres. Curr Opin Neurol. 2019;32(4):557-563.

46. Wesselman LM, Hooghiemstra AM, Schoonmade LJ, de Wit MC, van der Flier WM, Sikkes SA. Web-based multidomain lifestyle programs for brain health: comprehensive overview and meta-analysis. JMIR Ment Heal. 2019;6(4):e12104.

47. Cattaneo A, Cattane N, Galluzzi S, et al. Association of brain amyloidosis with pro-inflammatory gut bacterial taxa and peripheral inflammation markers in cognitively impaired elderly. Neurobiol Aging. 2017;49:60-68.

48. Lozano AM, Fosdick L, Chakravarty MM, et al. A phase II study of Fornix deep brain stimulation in mild Alzheimer's disease. J Alzheimer's Dis. 2016;54(2):777-787.

49. Bagley B. Point-of Care Registries | Proactively Manage Chronic Care Conditions. https://edhub.ama-assn.org/steps-forward/module/ 2702745. Accessed October 3, 2019.

50. Hellmuth J, Rabinovici GD, Miller BL. The rise of pseudomedicine for dementia and brain health. J Am Med Assoc. 2019;321(6):543-544.

\section{SUPPORTING INFORMATION}

Additional supporting information may be found online in the Supporting Information section at the end of the article.

How to cite this article: Frisoni GB, Molinuevo JL, Altomare D, et al. Precision prevention of Alzheimer's and other dementias: Anticipating future needs in the control of risk factors and implementation of disease-modifying therapies. Alzheimer's Dement. 2020;1-12. https://doi.org/10.1002/alz.12132 